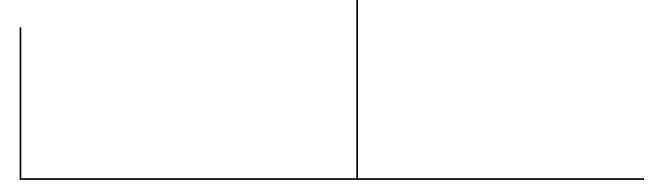

Rev. Latinoam. Psicopat. Fund., VI, 3, 144-153

\title{
Administração forçada de antipsicóticos a presos pela Sistema Judicial dos EUA: dois casos atuais
}

\author{
Mônica Teixeira
}

Durante o primeiro semestre de 2003, jornais médicos e leigos de língua inglesa registraram o andamento da perseguição judicial a dois homens mantidos à disposição da lei nos Estados Unidos: Charles Sell, dentista, preso desde 1997 sem culpa formada, sob acusação de fraude, diagnosticado como sofrendo de "transtorno delirante, tipo persecutório”; e Charles Laverne Singleton, condenado à morte por ter matado, em 1979, Mary Lou York, balconista, diagnosticado "esquizofrênico" em 1983. Em ambos os casos, o governo pediu às cortes de justiça que ordenassem a administração forçada de antipsicóticos aos presos, para obter, num caso, “competência para julgamento” e, noutro, a sanidade mental que torna constitucional uma execução. Os casos, embora dessemelhantes em sua minúcia, têm em comum apresentarem aspectos do pensamento dos profissionais do direito, e da saúde mental, a respeito do doente mental, e de como o uso de antipsicóticos altera essa sua condição. Ambos envolvem a mesma corte federal de apelação - a Corte de Apelações para o Oitavo Circuito, sediada em St. Louis, Missouri -, e a Suprema Corte dos Estados Unidos. 


\section{O que está em questão no caso Sell, para a Suprema Corte}

Em maio de 1997, Charles Sell foi acusado de requerer pagamento de seguros por sinistros fictícios. A história de sua doença mental precede, em muito, a data da acusação: segundo os registros da Justiça, começa em 1982, quando Sell foi hospitalizado pela primeira vez. Na ocasião, o dentista acreditava que o ouro das obturações havia sido contaminado por comunistas (Charles Sell era membro de uma organização de ultra direita do Missouri); foi tratado com antipsicóticos e mandado para casa. Em 1984, chamou a polícia dizendo que um leopardo tomava um ônibus na frente de seu consultório; pediu depois que a polícia atirasse nele próprio. Novamente foi hospitalizado, tratado com antipsicóticos, e liberado. Na época de seu indiciamento, contou a policiais que falara com Deus. Segundo Sell, Deus afirmou que cada agente do FBI morto por ele seria uma alma a mais salva.

A Constituição dos Estados Unidos requer que o doente mental acusado de crime apresente uma certa "competência para ser julgado". Os textos legais descrevem essa competência, por meio de "funcionalidades": habilidade para se consultar racionalmente com o advogado, para ajudá-lo em sua defesa, capacidade de entender os procedimentos tomados contra ele. Por isso, quando a primeira acusação foi apresentada, o juiz pediu uma avaliação psiquiátrica de Sell; com base nela, considerou o réu “competente”, e liberou-o sob fiança. No começo de 1998, o governo o acusou de ter tentado intimidar uma testemunha. Na audiência em que teve revogada a fiança, Sell gritou, insultou o juiz, cuspiu em seu rosto. Um psiquiatra informou que Sell não dormia, esperando o FBI invadir sua casa. Nessa altura, outras acusações haviam se juntado à primeira: fraude postal, fraude contra o sistema de saúde, e lavagem de dinheiro. Mais tarde, Sell foi acusado também de tentar matar o agente do FBI encarregado de prendê-lo, e um antigo empregado que testemunharia contra ele. Essas últimas acusações, no entanto, foram postas de lado porque poderiam ser o resultado do "transtorno delirante” de Sell, segundo as cortes.

Seis meses depois, Sell pediu reavaliação de sua "competência para o julgamento". Com base em laudo psiquiátrico, o juiz o declarou "mentalmente incompetente para ser julgado". Determinou então sua hospitalização por quatro meses no Centro Médico para Prisioneiros Federais do Missouri, ao fim dos quais esperava ouvir uma avaliação sobre a possibilidade de Sell recobrar as habilidades necessárias para o julgamento. Com dois meses de hospitalização, um psiquiatra e um psicólogo do Centro recomendaram que ele passasse a tomar antipsicóticos. Sell recusou-se; o Centro Médico insistiu, argüindo que o preso, sem medicação, representava um risco de segurança para quem estivesse perto dele. O Juiz autorizou a medicação forçada. Os advogados do acusado apelaram a uma Corte 
Distrital que manteve a decisão a favor da medicação forçada. Sell recorreu mais uma vez, agora à Corte de Apelações para o Oitavo Circuito (de cortes federais; para cortes de 7 Estados: Arkansas - que quer executar Singleton; Missouri caso Sell; Dakota do Norte, Dakota do Sul, Nebraska, Iowa, Minnesota) e perdeu novamente.

Da primeira decisão à terceira, o motivo pelo qual o governo teria o direito de medicar um doente mental contra sua vontade mudou. A Corte Distrital e a Corte de Apelos afirmaram a decisão pela medicação forçada com antipsicóticos, não mais com base no risco potencial à segurança alheia, e sim por considerarem que o interesse do governo em perseguir e apenar quem ofende a lei é maior do que o direito do preso de manter sua integridade corporal e de ter um julgamento justo. Esse debate - sobre os pesos relativos entre os interesses do Governo e os direitos do indivíduo - diz respeito à Constituição dos Estados Unidos. Sell apelou em 2002 à Suprema Corte, que aceitou a apelação e se pronunciou em junho de 2003. Justice Breyer, que escreveu a Opinião subscrita pela maioria da Corte, apresentou assim a questão a ser tratada: “A administração forçada de antipsicóticos para tornar Sell competente para ser julgado o priva, inconstitucionalmente, de sua liberdade de rejeitar tratamento médico?”.

\section{Intervêm as Associações}

O debate sobre o direito das autoridades de medicar doentes mentais à força com antipsicóticos interessa às associações dos Psiquiatras, dos Psicólogos, e dos Médicos e Cirurgiões, que apresentaram moções à Suprema Corte expondo suas posições sobre o caso, na condição de "amigos da corte": amicus curiae. A moção da APA (American Psychiatric Association) defende a "medicação involuntária" do réu doente mental para "restabelecer sua competência para o julgamento", sob basicamente uma condição: a de que o tratamento seja "medicamente apropriado", isto é, indicado para o réu mediante “a ponderação normal dos riscos de efeitos adversos e dos benefícios” que ele poderá trazer. Segundo a Associação dos Psiquiatras, o direito dos réus à integridade do próprio corpo é menos importante que o interesse governamental em elucidar um crime, condenando quem o tenha cometido. A Associação dos Psiquiatras sustenta seu argumento numa confiança indisputada no tratamento com antipsicóticos, em particular nos mais recentes, introduzidos a partir da década de $1990 .{ }^{1}$

1. É certo que quando se trata da adesão à medicação antipsicótica, a APA tem a sustentação dos psiquiatras dos EUA: em 2002, eles prescreveram 15 milhões de receitas apenas de 
“A análise é a mesma seja ou não a droga um antipsicótico”, diz o texto da moção, já em seu sumário. E mais adiante, "Antipsicóticos devem ser tratados como outros medicamentos", ao que se segue: "Virtualmente toda medicação, psiquiátrica ou não-psiquiátrica, envolve riscos de efeitos colaterais”. Quando se trata de antipsicóticos de primeira geração (haloperidol, flufenazina, clorpromazina, tioridasina), há bem conhecidos e muito problemáticos efeitos colaterais, que o texto vai descrevendo: acatisia - agitação motora, freqüentemente caracterizada por uma impossibilidade em ficar sentado; parkinsonismo; discinesia tardia; sedação... Mesmo com tantos inconvenientes, diz a Associação, a medicação antipsicótica de primeira geração foi “... freqüentemente o essencial, insubstituível tratamento para as doenças psicóticas, em especial para a esquizofrenia”. A chegada dos antipsicóticos "atípicos” (clozapina, risperidona, olanzapina, quetiapina) com "um perfil mais favorável de efeitos colaterais” (por isso são ditos atípicos), de acordo com a história contada pela Associação dos Psiquiatras, aperfeiçoa o que já era bom, e estende o campo para além das esquizofrenias, em direção a "psicoses difíceis de tratar" como, justamente, se diz do transtorno delirante diagnosticado em Charles Sell. Os benefícios são de tal monta, e a esquizofrenia uma doença tão horrível, conta a moção, que os efeitos colaterais se tornam aceitáveis; e, além do mais, podem ser controlados pelo médico que assiste ao preso.

Uma vez afirmados a força do tratamento com antipsicóticos e o incontroverso de sua indicação, a Associação pode fundamentar nela a prevalência do interesse do Governo em obter "competência para o julgamento" sobre o direito do preso à sua integridade física: a administração de antipsicóticos será, sempre, para o bem do preso, qualquer que seja ele. Medicar com antipsicóticos é o "medicamento apropriado", e "a Corte não deve ignorar os custos reais de deixar um réu sem tratamento, quando ele precisa desse tratamento”. O fato de o doente mental concordar ou não com o tratamento não incomoda a Associação: a concordância não é mencionada na discussão sobre o standard do tratamento com antipsicóticos. A pergunta do juiz, sobre a liberdade constitucional de rejeitar tratamento médico, também não mereceu atenção da APA. Não faz sentido, tal é a avaliação favorável sobre a efetividade das drogas típicas e atípicas.

Não é o entusiasmo pela prescrição de antipsicóticos o que move a outra APA (American Psychological Association) a apresentar recomendações à Suprema Corte. Depois de apontar que o debate é em torno de um preso não-

risperidona e olanzapina. A classe de antipsicóticos é a quarta mais consumida nos Estados Unidos, atrás dos anti-hipertensivos, antidepressivos e drogas para úlcera. Parte do sucesso comercial se deve ao alargamento da indicação dos atípicos para além do tratamento da esquizofrenia, apresentado como um indicador de suas qualidades terapêuticas. 
violento, que sequer teve definidas suas responsabilidades frente às acusações, a moção da Associação dos Psicólogos afirma a importância do direito à integridade do corpo; classifica os antipsicóticos de "drogas poderosas que afetam a química cerebral”, diferentes, portanto, de outras classes de medicamentos; e traz para o primeiro plano o fato de os efeitos colaterais dos antipsicóticos poderem afetar a conduta do réu durante o julgamento - o que pode impressionar desfavoravelmente o Juiz e o Júri - e sua habilidade de comunicação com o advogado. A partir desses três pontos, a Associação recomenda que a corte, quando confrontada com a questão, primeiro "explore as possibilidades do tratamento não-medicamentoso para cada réu em particular”. Segundo a moção, o que deve ser discutido é o processo de tomada de decisões em casos de medicação forçada de presos não-violentos. Dada a importância dos direitos em jogo, diz a APA no início de sua argumentação, como regra, primeiro as cortes devem exigir do Governo que se certifique de não haver nenhum tratamento nãomedicamentoso eficiente para a "restauração da competência para o julgamento" (o uso de "terapias psicossociais e de comportamento" é citado) para poder levar a efeito a medicação forçada. As drogas antipsicóticas, a Associação não ousa deixar de assinalar, "podem de fato ser altamente efetivas e, em muitos casos, apropriadas do ponto de vista médico”, mas para chegar até elas, as cortes devem ser persuadidas, caso a caso, de que as psicoterapias não funcionam.

Feita essa parte do argumento, a Associação discute pontos de fundo menos corporativista. Esclarece que o interesse do Governo na medicação forçada não é restaurar a saúde mental do preso, mas apenas obter "competência para o julgamento" - o que não é a mesma coisa. Por outro lado - e esse é um ponto interessante, ao qual a Associação dedica poucas linhas - "drogas antipsicóticas não são desenhadas para desenvolver habilidades e capacidades; na verdade, a intenção delas é suprimir sintomas de certos transtornos mentais”. Observa, também, que se um paciente toma antipsicóticos voluntariamente, as chances de sucesso e de menores inconvenientes aumenta, já que terapeuta e paciente podem discutir ajustes da medicação, seja no que toca às doses, seja no que toca à escolha da droga específica.

A Associação também nota que as cortes devem olhar com detalhe se a medicação é, de fato, indicada ao "transtorno específico de cada réu", contrapondo-se à tendência dos psiquiatras de ampliar o campo do uso dos antipsicóticos atípicos. "Muitas doenças mentais", informa cuidadosamente a moção, "que guardam alguma semelhança entre si respondem de maneira muito diferente à medicação”. Cabe notar que o doente mental não foi mencionado, e sim a doença. Não se justifica, continua o texto, tratar com drogas antipsicóticas alguém que sofre de um certo transtorno "apenas porque essas drogas beneficiam pacientes com outro transtorno”. Esse é um ponto fraco da argumentação 
apresentada pela Associação dos Psiquiatras: os benefícios dos antipsicóticos atípicos não estão tão bem estabelecidos, segundo os cânones da medicina baseada em evidências, para além das esquizofrenias. É o caso de quem é diagnosticado como portador de "transtorno delirante, tipo persecutório": não há suficientes estudos controlados, porque esse diagnóstico do DSM-IV é raro, e recente (de 1987); porque dificilmente os diagnosticados aceitam a medicação, uma vez que os profissionais de saúde são vistos como perseguidores, e porque a introdução das drogas é recente.

A novidade das drogas traz um problema também no que toca ao difícil assunto dos efeitos colaterais: não há informações sobre os resultados de seu uso de longo prazo. Já se sabe, no entanto, diz a moção, que clozapina, o gold standard entre os atípicos, apresenta o risco de causar agranulocitose, “desaparecimento potencialmente fatal de células brancas”; que há casos em que a risperidona e a olanzapina resultam em efeitos neuromusculares semelhantes aos das drogas de primeira geração; e que a quetiapina pode causar catarata. Dada a importância dos direitos em debate, as cortes devem se acautelar: primeiro, repetirá varias vezes a APA dos psicólogos, há que se verificar a efetividade dos tratamentos não medicamentosos.

A Associação dos Médicos e Cirurgiões (Association of American Physicians \& Surgens), “desde 1943 dedicada aos mais altos padrões éticos do Juramento de Hipócrates e a preservar a santidade da relação médico-paciente e a prática da medicina privada”, toca em aspectos deixados de lado pelas duas APAs. "Não é civilizado autorizar um médico da prisão a administrar, segundo sua discricionariedade, qualquer quantidade e qualquer tipo de medicação antipsicótica, apesar das objeções de um prisioneiro pacífico”. A Associação dos Médicos e Cirurgiões anexou à sua moção os testemunhos do psicólogo e do psiquiatra do Centro Médico que avaliou o Doutor Sell, para patentear sua indignação. Neles, o psiquiatra James Wolfson afirma à Corte que pretende usar ziprazodona para tratar Sell, medicamento que ele próprio descreve como “experimental” na Europa; e o psicólogo clínico DeMier que, em sua experiência, acompanhara até ali dois casos de transtorno delirante tratado com medicamentos (não prescritos por ele, pois psicólogos não prescrevem), sendo apenas um com antipsicóticos atípicos, aqueles que Wolfson pretendia prescrever a Sell.

\section{O que decidiu a Suprema Corte}

A Suprema Corte anulou a decisão da Corte de Apelações para o Oitavo Circuito, de permitir a medicação forçada de Charles Sell, suposto pela Corte como não-perigoso, com base apenas no interesse do governo de "restaurar a 
competência para o julgamento"; contemplou teses da Associação dos Psicólogos, e dos Médicos e Cirurgiões, mas não as da Associação dos Psiquiatras. Segundo a decisão (por 6 votos a 3), haverá casos em que a administração forçada de antipsicóticos para obter a competência seja constitucional; são casos raros, diz o Juiz Breyer, que devem atender quatro condições: primeiro, o interesse do governo em levar o preso a julgamento deve ser importante - no caso Sell, esse interesse tem sua importância diminuída porque a recusa em tomar a medicação é o que mantém Charles Sell confinado há 5 anos, tempo maior do que a pena prevista para o crime pelo qual ainda será acusado; segundo, a probabilidade de a administração forçada de drogas vir a tornar o preso competente precisa ser substancial e, ao mesmo tempo, pouco substancial a probabilidade de os efeitos colaterais prejudicarem a aparência do réu perante o Júri e o Juiz, arriscando a justiça do julgamento; terceiro, a medicação deve ser provada necessária para "restaurar a competência", e aqui o Juiz registra a controvérsia entre as duas APAs a respeito da eficiência da medicação; quarto, a administração forçada deve se dar no melhor interesse médico à luz da condição do preso. O juiz Breyer não encontrou essas condições. No entanto, diz a Suprema Corte, as condições para a constitucionalidade da administração forçada não são tão estritas se o preso é "perigoso"; portanto, recomenda às cortes que, em vez de procurar justificar a medicação forçada para "a restauração da competência”, o façam com base no risco à segurança representado pelo preso. Os outros juízes divergiram da admissibilidade do apelo pela Corte Suprema; por isso, não discutiram a questão de mérito.

\section{Charles Singleton, que espera a morte desde 1979}

Aos 19 anos, Charles Laverne Singleton esfaqueou e matou Mary Lou York, balconista de uma mercearia em Hamburg, no Estado do Arkansas. Preso, foi julgado e condenado à morte ainda em 1979 (o crime aconteceu em junho). A execução foi marcada pela primeira vez para 4 de junho de 1982, e suspensa, pela primeira vez, no dia 1 de junho. Em 1983, Singleton foi diagnosticado como sofrendo de "esquizofrenia paranóide", e começou a ser tratado com antipsicóticos. Em 1986, a sentença foi comutada para prisão perpétua sem direito a condicional; em 1989, reafirmada. Em 1987, Singleton passou a ter alucinações visuais, e a reclamar que sua cela estava possuída por um demônio. Segundo os registros da Corte de Apelações do Oitavo Circuito, ele "acreditava que o médico da prisão havia instalado um dispositivo em seus ouvidos, que seus pensamentos eram retirados dele enquanto ele lia a Bíblia, e que os outros presos sabiam o 
que ele estava lendo”. O psiquiatra encarregado recomeçou o tratamento com antipsicóticos, mas meses depois Singleton se recusou a continuar. Entrou então pela primeira vez no regime de medicação forçada, do qual tem entrado e saído várias vezes ao longo dos anos no corredor da morte.

Em 1992, Singleton alegou, nas cortes do Arkansas e na Corte de Apelações do Oitavo Circuito, faltar-lhe "competência” para ser executado. A Constituição dos EUA não permite a execução de doentes mentais, se eles não podem entender a natureza e as razões da punição que vão receber. Pediu a suspensão da medicação forçada, afirmando que, através dela, o estado do Arkansas pretendia fazê-lo parecer competente para a execução. Em 1995, a Corte Distrital achou-o "competente" - naquele momento, Singleton tomava antipsicóticos voluntariamente. De 1995 para cá, o preso ora é medicado à força, ora não é medicado, ora aceita os antipsicóticos. Sempre segundo o registrado nas sentenças, ele acredita ser a Suprema Corte, e Deus; acredita que vai ser solto; que será executado, mas depois revivido pelo poder dos juízes. Em janeiro de 2000, teve a execução marcada para o mês de março. Mais uma vez, seus advogados alegaram que o Estado do Arkansas não teria permissão para medicálo à força, tornando-o “competente”, para então executá-lo. Um psiquiatra avaliou sua condição em meados de 2000, achando-o pior do que em 1995, quando da última avaliação.

Em outubro de 2001, com base na avaliação, e na história de Singleton, um painel de três juízes da Corte de Apelações decidiu suspender permanentemente a execução, e transformar a sentença em prisão perpétua. Mas em fevereiro de 2003, a Corte de Apelações anulou a decisão não unânime do painel de juízes, e afirmou ser constitucional a administração forçada de medicação antipsicótica a um prisioneiro, mesmo quando a data da execução estiver marcada, tornando-o dessa forma competente para ser morto. Em maio de 2003, a Suprema Corte aceitou apreciar o caso, mas ainda não há data marcada para que ela aconteça. Uma primeira conferência sobre o caso está agendada para o mês de setembro de 2003.

\section{O que está em questão, no caso de Singleton, segundo os juízes dissidentes}

Com a última decisão da Corte de Apelações do Oitavo Circuito - de que Singleton pode ser medicado à força, mesmo que resulte daí a competência para sua execução -, concordaram seis juízes. Por eles, escreveu o juiz Wollman. Ele afirma o interesse do governo em buscar a punição dos culpados; considera 
a medicação boa para Singleton; observa que o preso gosta dela, e daí: "Eligibility for execution is the only unwanted consequence of the medication”. A decisão, noticiada na primeira página do New York Times, repercutiu na seção de cartas. Nesse caso, a Associação Psiquiátrica e a Associação Médica condenam a medicação forçada com veemência, baseadas no Código de Ética, uma vez que a administração forçada do antipsicótico, se é ela o meio para autorizar a execução, então não pode ser considerada do interesse do paciente.

Mas quatro juízes divergiram da maioria. Escreveu por eles Gerald Heaney. Num bonito e indignado voto, o juiz - nascido em 1918, natural de Minnesota, nomeado por Lyndon Johnson - expõe questões mais fundamentais sobre os psicóticos do que as associações médicas e de psicólogos. "Charles Singleton sofre de doença mental que o faz psicótico. Às vezes, ele tem sido forçado a tomar poderosas drogas psicotrópicas”, começa o juiz Heaney, "outras vezes, toma essa medicação voluntariamente. As drogas freqüentemente mascaram sua psicose latente. A maioria acredita que isso o torna passível de execução. Eu acredito que executar um homem que está severamente perturbado sem tratamento, e possivelmente incompetente quando tratado, é o pináculo daquilo que o juiz Marshall chamou de 'a barbaridade insensata da vingança precisa'”. Depois de historiar as idas e vindas do caso, Heaney observa que a execução de um insano não se coaduna com os ideais da sociedade civilizada; e passa então a discutir se um doente mental recebendo tratamento deixa de ser doente mental. "Drogas antipsicóticas”, escreve o juiz, como a Associação dos Psicólogos, mas mais radicalmente, "meramente acalmam e mascaram os sintomas psicóticos", razão pela qual "receber tratamento não é sinônimo de estar curado". Portanto, ele continua, "quando a medicação antipsicótica resulta em um estado mental melhorado, o paciente está apenas apresentando aquilo que tem sido definido como sanidade 'artificial' ou 'sintética'”.

Além de não se poder dizer, então, que o doente mental tomando antipsicóticos deixe de ser psicótico, há também a imprevisibilidade do resultado do uso dessas drogas, singular para cada singular paciente. Debruçando-se sobre os registros a respeito de Singleton, o juiz observa que "o plano de tratamento de sua doença mental tem sido consistentemente fluido". Apesar de estar sob tratamento, e há tantos anos, Singleton deixou ao último psiquiatra que o avaliou a impressão de continuar psicótico; e de que seria bastante difícil "assegurar (...) o padrão de competência no exato momento de sua execução”. Com base no histórico médico, Heaney assinala que as "drogas poderosas" apenas "emudecem”, temporariamente, a "insanidade" de Singleton. "Sob a máscara da estabilidade, ele permanece insano. A proibição do caso Ford [o mais importante precedente] de executar os insanos deve ser aplicada com não menos força a Singleton do que a prisioneiros não tratados”. 
O voto dissidente de Heaney também aborda o problema da conduta dos médicos pegos nessa situação. O juiz lembra que a ética da Associação Médica Americana e da Associação dos Psiquiatras, ambas, proíbem seus membros de participar da execução dos condenados à morte - uma vez que os médicos estão obrigados pelo Juramento de Hipócrates a agir apenas no melhor interesse médico de seus pacientes. Um médico que trata um prisioneiro condenado à morte se vê numa posição impossível: "tratando o prisioneiro pode trazer alívio de curto prazo, mas no limite resultará na execução; e, não tratando, condena o paciente a um mundo como o de Singleton, povoado de alucinações e delírios”. A decisão de medicar à força o condenado à morte afronta a tradição das cortes, diz o juiz, de respeitar a ética médica e levar em conta suas normas de conduta.

E qual é, então, a solução para os dilemas colocados pela decisão da maioria que pretende ser constitucional executar um doente mental submetido a medicação forçada? O Juiz Heaney apresenta a resposta: a suspensão permanente da execução. Com essa medida, os médicos ficam livres para usar os antipsicóticos - mesmo à força - se for no melhor interesse do paciente. Também se mantém a tradição do direito americano - que proíbe a punição cruel através da Oitava Emenda. Afinal, Charles Singleton - medicado ou não - permanece insano, enquanto o Governo do Arkansas não desiste de executá-lo.

Números

Segundo o departamento de Justiça dos EUA, no últimos 12 meses, o sistema prisional tratou 285 réus doentes mentais sem "competência para o julgamento”, como Charles Sell; deles, 59 foram medicados à força. 